CUPAUAM. 19-1992, 67-93

\title{
NUEVAS APORTACIONES AL ESTUDIO DE DOS ESTELAS DECORADAS HALLADAS EN LA CUENCA SUR DEL DUERO (Beira Alta, Portugal)
}

JOSE LUIS MARTIN MOMPEAN

\section{Resumen}

En el presente trabajo hemos realizado el estudio de dos nuevas estelas decoradas del tipo II de Almagro Basch que fueron halladas en la región de Beira Alta (Portugal), y cuya valoración nos ha permitido extraer nuevas e interesantes aportaciones al confuso panorama que rodea esta manifestación cultural que caracteriza parte del Bronce Final peninsular.

\section{Summary}

In the present article we have acomplished the study of two new stelae, type II of Almagro Basch, found in the region of Beira Alta (Portugal). Their valuation has allowed us to extract new and interesting contributions from the confuse panorama that surrounds this cultural manifestation that characterizes part of the later Bronze Age in the Iberian Peninsule.

\section{INTRODUCCION}

Hace unos meses, bajo la dirección del profesor M. Bendala, iniciamos el presente trabajo con la intención de recuperar y valorar en su medida la información que nos pueden ofrecer dos estelas decoradas halladas en territorio portugués, en Fóios y Baraçal, respectivamente, en la región de Beira Alta. Ambas piezas fueron publicadas hace algunos años (F. P. Curado, 1984, 1986), pero sendos trabajos han pasado casi desapercibidos en los numerosos estudios que, con posterioridad a su fecha de publicación, se han realizado acerca del fenómeno cultural de las estelas decoradas del Suroeste.

Recientemente han sido publicados varios estudios monográficos sobre el mundo tartésico (M. E. Aubet, 1989 y La Cultura Tartésica y Extremadura, 1990), en los cuales se han incluido algunas notas referidas a las estelas de Fóios y Baraçal. A pesar de ello, creemos que los datos que pueden proporcionarnos estas piezas no han sido evaluados todavía en profundidad, por lo que hemos estimado necesaria y oportuna la realización del trabajo que presentamos a continuación. 


\section{LAS ESTELAS DE FOIOS Y BARAÇAL (1)}

- La estela de Fóios (Fig. 1): es un bloque de esquisto, de afloramientos locales, que fue encontrado, enterrado a poca profundidad, junto a la aldea de Fóios (en el curso inicial y en la margen derecha del río Côa).

El monumento fue grabado por piqueteado seguido de incisión (por abrasión) con una punta metálica bastante fina, dando lugar a un trazo interior más estrecho y profundo. Tiene una altura máxima de $93 \mathrm{~cm}$, una anchura máxima de $66 \mathrm{~cm}$ y un grosor entre 7 y $9 \mathrm{~cm}$.

Una fractura en la parte superior izquierda ha destruido la punta de la lanza (2). El escudo es de cuatro anillos ligeramente ovalados, siendo escotados los dos intermedios (con escotadura en U bastante abierta). En cuanto a la espada podemos resaltar su atipismo; es notoria la separación entre la lámina y la empuñadura, resaltando en ésta la existencia de dos pares de pequeños orificios que representan los clavos de fijación a la lámina: estos orificios están separados $2 \mathrm{~cm}$ en un par y $3 \mathrm{~cm}$ entre pares, perpendicularmente a la empuñadura y junto a ella, existen dos pares de trazos con cerca de $1,5 \mathrm{~cm}$ cada uno, pero no es seguro que sean originales ya que la pátina es diferente y están grabados a bisel, contrariamente a la restante incisión que es bastante más abierta.

La anchura del grabado, bastante superficial debido a la dureza del soporte (que no muestra preparación inicial) tiene una media de $0,5 \mathrm{~cm}$; la incisión interior no tiene más de $0,2 \mathrm{~cm}$ de longitud, lo cual hace ver que la profundidad podría ser de $0,3 \mathrm{~cm}$ aproximadamente.

Localización del hallazgo: sitio das Eiras, freguesía de Fóios, concelho de Sabugal, distrito de Guarda. Coordenadas UTM 29TPE790622.

- La estela de Baraçal (fig. 2): se encontró tumbada en mitad de un camino cerca de la aldea de Baraçal. Fue utilizado un bloque granítico, de color grisáceo claro y de grano fino, procedente de afloramientos locales. Tiene una altura de $92 \mathrm{~cm}$, una anchura de $83 \mathrm{~cm}$ y un grosor máximo (en la parte central de la pieza) de $29 \mathrm{~cm}$.

Por el tratamiento diferenciado a que fue sujeto, puede dividirse este bloque en dos partes distintas: un "cuerpo", todo él pulido y donde fueron esculpidas unas armas, y un "pie" o "cuña", apenas desbastado y de mayor anchura para que, clavado en el suelo, diese mayor estabilidad al monumento.

La cara anterior es plana y en ella sobresale la decoración, pues está realizada con la técnica de relieve. Por el realismo de la escultura, parece evidente que las propias armas podrían haber servido de molde o esbozo inicial, después del cual se desbastó toda la cara anterior, lo que permitió hacer resaltar los elementos figurados.

La cara posterior fue labrada desde el centro del "cuerpo" hacia los extremos, disminuyendo el grosor en los bordes y dando lugar a una forma convexa un poco pronunciada. Asimismo, en la cara posterior también es clara la separación entre "cuerpo" y "cuña".

(1) En cuanto a la parte descriptiva de las piezas hemos mantenido casi en su totalidad la información que proporciona F. P. Curado en su trabajo original.

(2) F. P. Curado indica la posible existencia también ahí de la representación de un espejo, aunque creemos, tras observar las fotografias de la estela, que no existe ninguna base para tal afirmación, pues esa parte de la pieza se encuentra completamente destruida. 


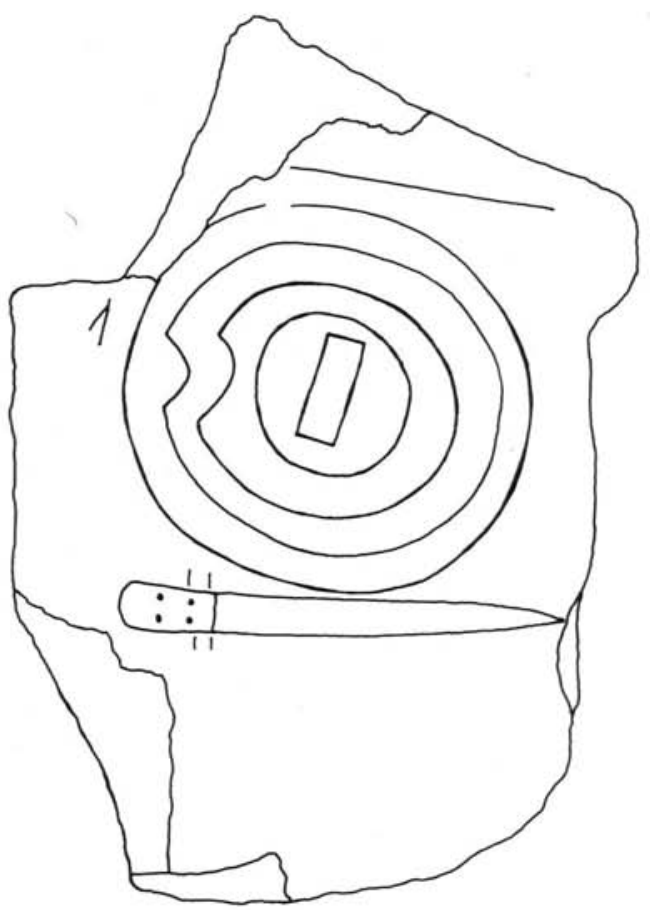

Figura 1: Estela de Fóios, Sabugal (Guarda, Portugal). (Según F. P. Curado)

Figura 2: Estela de Baraçal. Sabugal (Guarda, Portugal). (Según F. P. Curado)

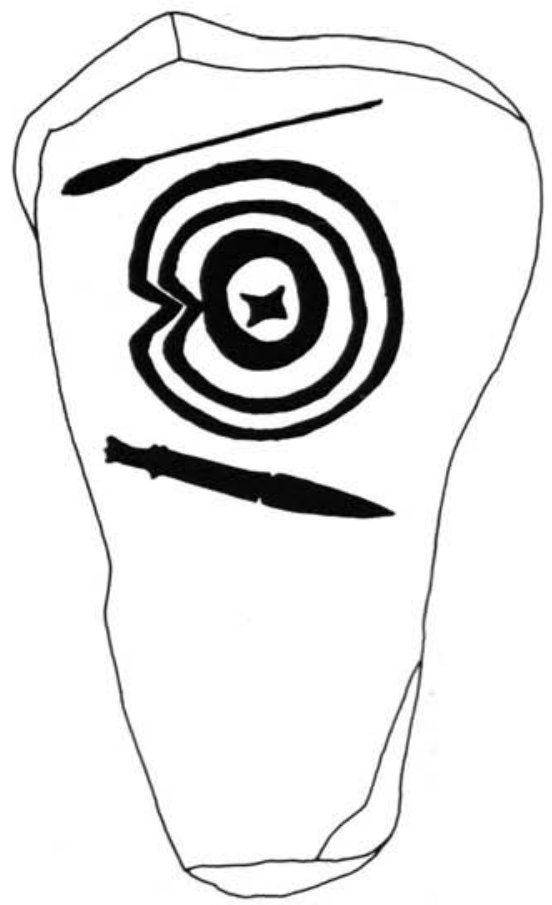


Si exceptuamos una pequeńa fractura junto a la punta de la espada y la diminución poco pronunciada del relieve en algunos puntos de la escultura causados por las rodadas de los carros durante el tiempo que estuvo tirada en el camino, así como algunos surcos en la cara posterior, que no afectan al conjunto, podemos decir que esta pieza se encuentra en perfecto estado de conservación.

La técnica utilizada en la realización de los elementos representados es el relieve. Este aspecto aporta nuevos y relevantes datos sobre las estelas pues es, frente a la continua aparición del grabado, la primera vez que se constata esta técnica en la Península Ibérica en este tipo de monumentos. La altura media del relieve es de $0,7 \mathrm{~cm}$. El escudo es de tres anillos concéntricos, siendo escotados los dos más exteriores. La espada es pistiliforme e idéntica a la descubierta en Vilar Maior (Sabugal) a pocos kilómetros al noreste. La punta de la lanza tiene una lámina larga y estrecha.

Localización del hallazgo: sitio das Piçarreiras, freguesía de Baraçal, concelho de Sabugal, distrito de Guarda. Coordenadas UTM 29TPE635742.

\section{ESTUDIO COMPARADO ASPECTOS GEOGRAFICOS}

Una cuestión que sorprende inicialmente en estas dos nuevas estelas, y que ya ha sido destacado en el título del artículo, es su localización geográfica, al norte de las líneas montañosas que constituyen el Sistema Central, y lo que es más interesante, situadas ya en la Cuenca del Duero, pues el río Côa vierte sus aguas a la misma. Insistimos en este punto porque en un trabajo de reciente aparición (J. A. Barceló, 1989, 192) se ha señalado que la estela de Baraçal había sido hallada en la Cuenca del Tajo (Beira Baixa portuguesa). Como puede apreciarse en el mapa de la zona (fig. 3) no existe ninguna duda sobre cuál es la posición geográfica de los lugares donde fueron descubiertas ambas estelas.

Es importante la aclaración de este dato, pues son las primeras estelas de este tipo que aparecen en este espacio natural, ya que las restantes habían sido halladas al sur del mismo, pasado el Sistema Central (excepto la estela de Valpalmas, en Zaragoza, que queda desplazada de lo que entendemos como región del suroeste peninsular y que descartaremos en este comentario inicial).

El hallazgo de estas estelas amplía notablemente el ámbito geográfico al que se venían asignando estos monumentos, no por su situación directa (pues la estela de Fóios no está a más de $12 \mathrm{Km}$ de distancia absoluta de la de San Martín de Trevejo) (M. G. de Figuerola, 1982, 173), sino por lo que representa la incorporación de un área geográfica completamente nueva.

En cuanto a su posición relativa respecto a las aparecidas en esta zona, el lugar del hallazgo es el más septentrional de los conocidos hasta ahora. Esto parece confirmar que las estelas del tipo más simple (II A) son más numerosas en esta región, idea sostenida desde hace tiempo, apartando a un lado por ahora la polémica sobre si son anteriores o no a aquellas más complejas.

La comarca a la que pertenece la población de Sabugal se encuentra frente a un posible paso natural que cruza las alturas de la Sierra de Malcata y, sorteando la barrera del Sistema Central, comunica las Cuencas del Duero y el Tajo. Este paso ha sido aprovechado tradicionalmente por las rutas de trashumancia, que antaño cubrían una mayor extensión. La Sierra de la Estrella recibía ganado de las tierras lusas que se encontraban entre el Tajo y el Guadiana, e incluso de Espa- 
ña. Los rebaños serranos pasaban el invierno en el Campo de Ourique, tras recorrer más de 400 $\mathrm{Km}$, y a ellos se unían ganados españoles de la Cañada Real Leonesa, que hasta la Restauración se ramificaba también por el Alemtejo.

Ya se ha señalado (M. E. Aubet, 1975, 157) que este tipo de actividad influyó en la elección de las zonas de asentamientos de los pueblos ganaderos situados en la Meseta Occidental, obligándoles a una serie de movimientos periódicos en busca de pastos en Extremadura y el valle del Guadalquivir durante el invierno, mientras que en verano buscaban las tierras altas de la Meseta. Esta trashumancia se acompañaría de contactos e intercambios esporádicos que explicarían la presencia de cerámicas procedentes de la Meseta en plena región de Tartessos (Setefilla) y, de igual manera, los hallazgos aislados de objetos de carácter tartésico en la zona oeste de la Meseta (broches de Sanchorreja, Avila, bronces del Berrueco, Salamanca y jarros de Coca, Segovia y Villanueva, Cáceres, entre otros). Estos materiales no demuestran por sí solos un comercio regular entre Tartessos y las regiones interiores peninsulares, sino que aparecen situados cerca de estas vías agropecuarias que conectarían ambos territorios.

En relación con estos contactos podemos subrayar la aparición de cerámica tipo Cogotas I en el norte de Portugal (tanto en poblados como en enterramientos), hecho que ha sido interpretado como producto de unos intercambios en los cuales las poblaciones de la Meseta buscaban en tierras portuguesas materias primas (especialmente metales) y elementos de prestigio de carácter atlántico (S. O. Jorge, 1988, 100).

Se trata pues, de un momento en el cual los contactos e intercambios, principalmente de índole económica, se amplían e interregionalizan, por lo que las vías de comunicación adquieren una importancia inusitada, a la vez que su control se torna fundamental para el desarrollo de aquellas comunidades beneficiadas por la generalización de esta circunstancia (M. Bendala, 1990, 23).

En tierras extremeñas hay una serie de vías naturales que se vertebran en torno a la falla Alemtejo-Plasencia, la cual atraviesa la zona más septentrional de la región en dirección SW-NE, desde Alburquerque hasta el Pto. de Tornavacas, cruzando los pasos de Puertollano (Aliseda) y los Castaños (Cañaveral) (M. I. Ongil y M. I. Sauceda, 1986, 156). En relación con esta larga falla, de más de $500 \mathrm{kms}$ de longitud, se pueden trazar dos líneas de comunicación con la Meseta Norte. Ambos caminos parten desde el importante vado de Alconétar, en la confluencia de los ríos Tajo y Almonte, dirigiéndose el primero hacia Salamanca por el Pto. de Béjar y el segundo hacia Avila por el paso de Tornavacas (A. Alvarez Rojas y J. Gil Montes, 1988, 308) (fig. 4).

Tanto la localidad de Fóios como la de Sabugal se encuentran muy cerca de aquellas rutas de comercio que, desde antiguo, relacionan la región del Suroeste peninsular con la comarca estannífera del Noreste, camino que se consolidará durante la dominación romana en la conocida Vía de la Plata (M. Bendala, 1985, 629). J. Alvar $(1980,47)$ señala que esta vía terrestre de intercambio y comercio podría estar en manos tartésicas, mientras que serían los gaditanos quienes controlasen la ruta marítima atlántica (Escimno de Quíos, siguiendo a Eforo, afirma que Tartessos traía el estaño aluvionario de la Céltica). La existencia de influencias tartésicas hasta la margen izquierda del Duero indicaría el lugar donde se realizarían las transacciones comerciales entre éstos y los intermediarios indígenas.

La misma región de la Beira posee explotaciones de cobre y estaño que, aunque por confirmar, pudieron haber estado en funcionamiento desde muy antiguo, convirtiéndose esta zona durante la Edad del Bronce en un importante centro de actividad metalúrgica, como así han señalado Tavares Proença (minas de Monforte y Juncal, en Castelo Branco, Beira Baixa) y A. 


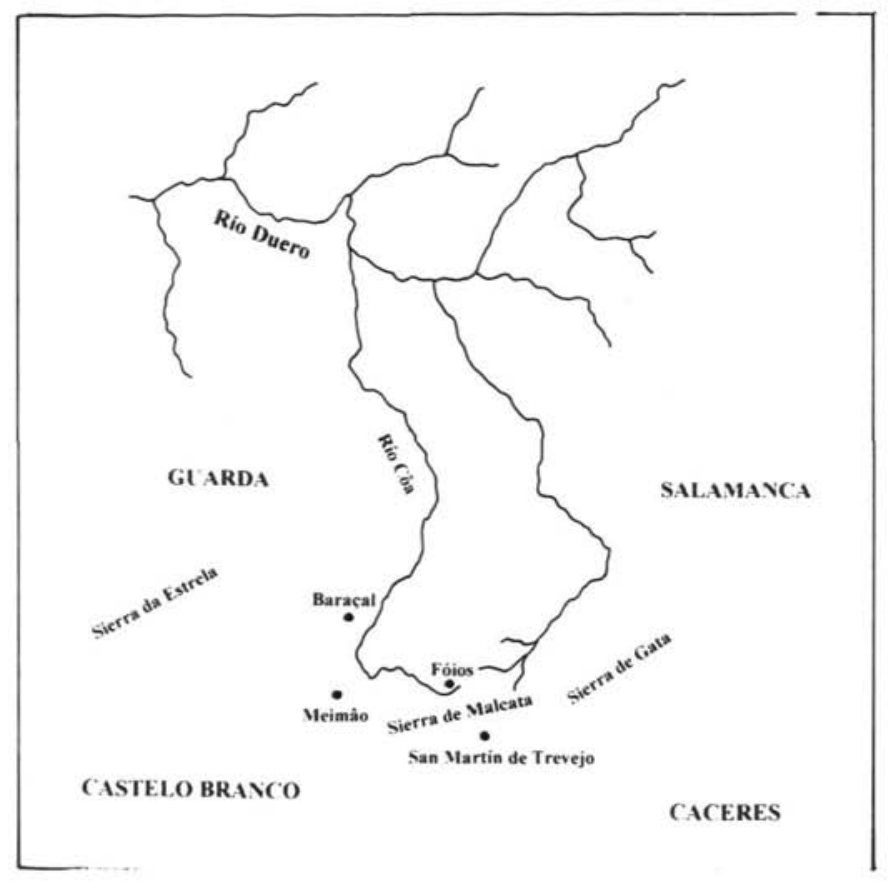

Figura 3: Mapa de la zona

Figura 4:

Vías naturales de comunicación en el Suroeste peninsular. (Según A. Alvarez Rojas y J. Gil Montes

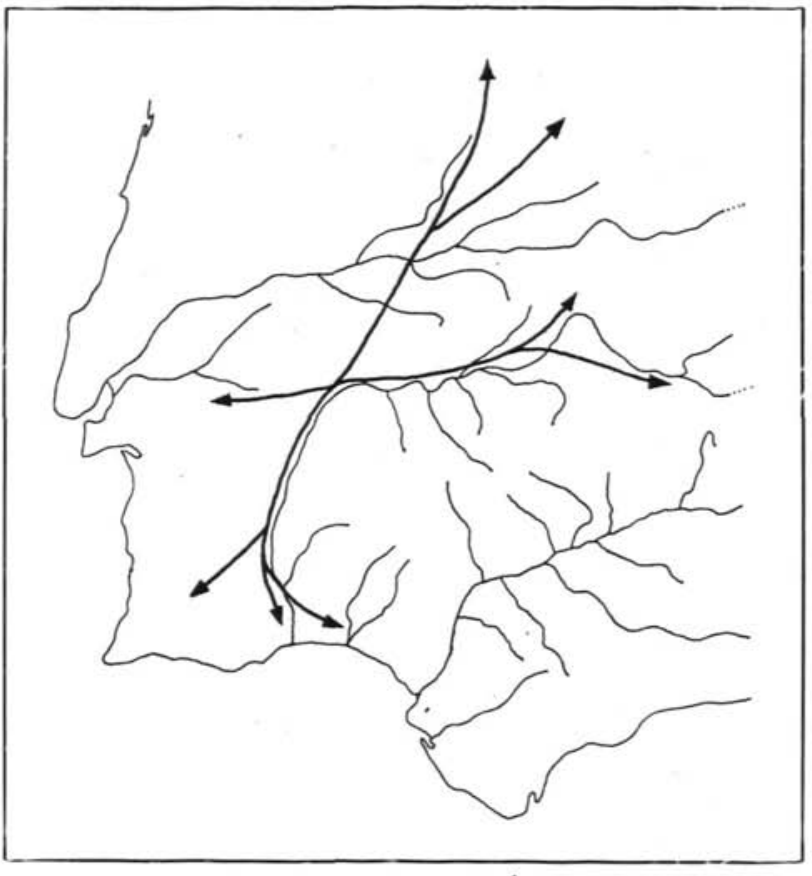


Coffyn (mina de Quarta Feira, en Sortelha, localidad próxima a Sabugal, Beira Alta) (A. Coffyn, $1976,26)$. Esta misma posibilidad fue apuntada ya por A. Vasco Rodrigues $(1958,225)$, quien señaló, además de estas posibles explotaciones mineras, las espléndidas condiciones físicas (a su buena posición geográfica se unen la fertilidad de sus terrenos, buenas defensas naturales y una temperatura agradable) que ofrecía la región del alto Côa a las comunidades de la época.

S. Oliveira Jorge $(1988,101)$ ha subrayado el interés que tendría estudiar el papel desempeñado por aquellas regiones fundamentalmente productoras de materias primas (Noreste, Beira Alta, Suroeste) y por otras que actuarían como áreas intermediarias (Extremadura portuguesa), factor que ocasionarían la aparición de importantes desigualdades en el control de la circulación de productos, originando a su vez asimetrías de poder en los grupos afectados. En este sentido, M. Bendala $(1990,23)$ ha indicado que la necesidad de controlar los territorios ricos en materias primas de especial importancia, para lo cual era esencial el completo dominio de las vías de comunicación, representaría una de las principales características del llamado Bronce Final Tartésico.

\section{ASPECTOS FORMALES}

No pretendemos repetir aquí las descripciones de ambas estelas, sino profundizar en esos aspectos ya resaltados que consideramos de interés, pues pueden aportar, como indicamos anteriormente, importantes novedades al estudio de estos monumentos.

\section{La estela de Fóios:}

a) Escudo: si lo comparamos con los escudos de las restantes estelas del tipo más simple observamos que no es el modelo habitual en estas representaciones. Se trata de un escudo compuesto por cuatro círculos o anillos concéntricos; de ellos, y esto es lo notable, los dos interiores poseen sendas escotaduras en forma de $\mathrm{U}$ bastante abierta (no existiendo ninguna duda al respecto), mientras que el anillo exterior está completamente cerrado, sin escotadura. No tiene representaciones de posibles remaches ni de claveteado. El asidero tiene una forma rectangular.

Formalmente, su paralelo más cercano y directo lo encontramos en el escudo que aparece en la estela de Torres Alocaz, Sevilla (D. Oliva Alonso, 1976, 390), con el que guarda numerosas semejanzas, si exceptuamos la diferente posición del asidero respecto a las escotaduras (perpendicular en éste, paralelo en aquél) y la forma de la misma (una simple línea recta en este último). Ambos coinciden en las escotaduras en $\mathrm{U}$ y en el número de anillos concéntricos.

El escudo con escotadura en $\mathrm{U}$ es inusual en las representaciones de las estelas decoradas, constituyendo estas dos piezas las únicas muestras que, por ahora, existen en la Península Ibérica de este tipo de arma defensiva. Resulta curioso que este tipo de escudo haya aparecido en dos estelas tan distantes geográficamente, y que prácticamente limitan y cierran, por ahora, el marco de distribución de estos monumentos, pues la estela de Fóios supone el hallazgo localizado más al norte, mientras que la de Torres Alocaz es el más meridional.

De todos los escudos conocidos en Europa de los que tengamos confirmación arqueológica, las características del escudo de la estela de Fóios (escotaduras en U bastante abierta) nos remiten a los ejemplares de la Europa del Norte y a la región atlántica (moldes de madera para escudos de Cloonlara y Annandale, Irlanda, y ejemplares del Museo de Copenhague, Dinamarca) (M. Almagro, 1966, 162). M. C. Fdez. Castro $(1989,284)$ ha recogido recien- 
temente las corrientes actuales sobre el origen de estos escudos, señalando ella misma que los escudos con escotaduras en $U$ tienen su origen o sus precedentes en las culturas centroeuropeas y nórdicas, muy influidas, especialmente las primeras, por la tradición cultural micénica debido a los constantes y variados contactos que mantuvieron. Los escudos con escotadura, que en un principio sería en $U$, se manifestarían de esta manera como una creación de carácter centroeuropeo (escudos de Pilsen, Checoslovaquia, y Herzsprung, Alemania) (E. Sprockhoff, 1954, 28). Esta creación tendría una gran aceptación en la Europa del Norte y en las regiones atlánticas, zona ésta última donde pudo producirse la transformación de la escotadura, pasando de la forma en U a V (muy posiblemente ocurriría en Irlanda, puesto que allí han aparecido escudos de ambas variantes) (A. Soutou, 1962, 521). A través de los contactos atlánticos establecidos desde la región irlandesa este tipo de escudo podría haber llegado a la Península Ibérica junto a diversos materiales de la misma procedencia. De todos modos, quedaría sin explicar la razón por la cual estos escudos han aparecido representados en estela situadas en zonas del interior, mientras que permanecen inéditos en regiones próximas a la costa atlántica.

En cuanto a los defensores de su origen mediterráneo, entre otros, H. Hencken $(1950,295)$ y J. M. Coles $(1962,156)$ coincidieron en apuntar que la Península Ibérica pudo convertirse en esta época en un foco secundario de distribución de materiales del Mediterráneo Oriental hacia regiones atlánticas, explicándose de esta manera la llegada de los escudos con escotaduras a la Europa atlántica. Estos mismos autores han observado que es bastante difícil rastrear la posible ruta que pudieron seguir estos escudos desde su lugar de origen hasta la Península, puesto que faltan restos de estas armas en todo el Mediterráneo Central. Como alternativa se ha propuesto la posibilidad, habiendo aceptado su origen oriental, de una vía de difusión que atravesando Centroeuropa se desligara en dos rutas alternativas que finalizaran respectivamente en la región irlandesa e ibérica, representando los escudos aparecidos en estas zonas los últimos modelos del final de la serie, y por lo tanto, muy diferentes respecto a los originales.

Continuando con esta hipótesis, se ha propuesto la existencia de dos caminos independientes en la difusión de este tipo de escudos que procederían del Mediterráneo Oriental; uno, con las escotaduras en U, que alcanzaría el norte de Europa tras atravesar el continente, y otro, con la escotadura en V, que llegaría hasta la Península Ibérica, finalizando ambas modalidades en Irlanda, motivo por el cual existen en esta región ejemplos de los dos tipos de escudo (J. M. Coles, 1962, 174 y M. Almagro Basch, 1966, 165). Esta posibilidad se ve ligeramente alterada por la existencia ya comprobada en la Península Ibérica de escudos con escotaduras en U.

Otra llamativa particularidad del escudo representado en la estela de Fóios es la ausencia de escotaduras externas, ya que, casi por regla general, los escudos de las piezas que responden a esquemas compositivos más simples (y ésta lo es) tienen escotaduras en $\mathrm{V}$ que afectan a los dos anillos exteriores (Ibahernando, El Carneril, Granja de Céspedes, Robledillo de Trujillo). Parece que, en estos casos, las escotaduras conservan aún su funcionalidad, habiéndola perdido totalmente en el escudo de la estela de Fóios, en el cual se les otorga un papel meramente formal o decorativo. Estos escudos con escotaduras interiores pueden suponer un modelo evolucionado o derivado de aquellos otros que mantienen las escotaduras exteriores, con una forma y sentido todavía efectivo. Cuando este carácter funcional se pierda, la escotadura ocupará únicamente el interior del escudo (sin afectar al anillo exterior), desempeñando una función exclusivamente ornamental, para desaparecer por completo en aquellos escudos que carecen de ella y que han sido datados en fechas más tardías (del s. VIII a. C. en adelante). 
b) Espada: como el elemento anterior, la espada sorprende por su atipismo, ya que pertenece a un modelo poco común, incluso bastante extraño, entre las armas representadas en el resto de las estelas decoradas. A pesar del esquematismo propio de estas figuras, no tan acentuado como en otros casos, se pueden apreciar claramente algunas características propias de esta espada que la convierten en un ejemplar único entre todos los conocidos hasta ahora. La zona del enmangue de la empuñadura se ha realizado con tal detallismo que permite distinguir claramente dos pares de pequeńos orificios que podrían representar los clavos para la fijación de la misma a la lámina de la espada. En cuanto a ésta, los bordes o filos corren paralelos hasta el extremo donde se unen en una punta bastante aguda. Por medio de una línea recta incisa se ha subrayado la diferencia entre el enmangue de la empuñadura y la lámina de la espada. En el siguiente apartado comentaremos la ausencia de empuñadura en la representación grabada de esta espada, pues esta característica inusual puede aportar algunos datos interesantes para la interpretación de las estelas decoradas.

Entre todas las representaciones de espadas que hay en las estelas no hemos encontrado ningún ejemplar similar a éste, debiendo buscar posibles paralelos tipológicos en aquellas espadas halladas en excavaciones, depósitos o hallazgos aislados que se han producido en la Península Ibérica, y que pueden ser asignados a la etapa cultural correspondiente a la realización de estos monumentos.

J. A. Barceló $(1989,192)$ ha sugerido que esta espada podría ser de influencia Rosnoën (Bronce Final I en Bretaña, con unas fechas entre 1100-1000 a. C.), o bien relacionarse con los puñales tipo Porto de Mós (Bronce Final Atlántico III, siglo IX a. C.), siendo, en cualquier caso, un rasgo arcaizante.

En cuanto a la segunda posibilidad, A. Coffyn $(1983,174$ y 1985, 171) señala que todos los ejemplares de puñales tipo Porto de Mós, excepto tres, se han encontrado entre los ríos Duero y Tajo. Este modelo de puñal se caracteriza por ser un arma corta, con ambos filos cortantes, tener una lámina triangular (algunas veces con los bordes paralelos en su parte superior) y una sección biconvexa; la empuñadura, de lengüeta bipartita, está perforada por varios agujeros (de dos a cinco), pero lo más común son tres perforaciones formando un triángulo. Según este autor, no es posible buscar un origen centroeuropeo para este tipo de arma, por lo que podemos estar ante una creación peninsular, como así lo atestiguan el gran número de ejemplares aparecidos.

Por lo que respecta a las armas de influencia Rosnoën, el único ejemplar existente en la Península Ibérica es la espada hallada cerca de Palencia (fig. 7). Muestra una lengüeta trapezoidal con dos remaches y una lámina triangular con los filos bien marcados, datándose en la segunda mitad del siglo XIII a. C. (A. Coffyn, 1985, pl. II-3).

Creemos que la posibilidad de relacionar la espada de la estela de Fóios con modelos Rosnoën es más acertada que una posible relación entre ésta y los puñales tipo Porto de Mós, cuya forma característica es sustancialmente distinta. En cuanto a la espada de Palencia, hemos apreciado que se aparta ligeramente de la forma representada en la estela, aunque esto no es obstáculo para aceptar idénticos orígenes para ambas armas, pues tales diferencias pueden ser debidas a diversos factores.

Otra característica que nos aleja de la posible relación entre esta espada y los puñales Porto de Mós es la longitud del arma grabada en la estela $(47 \mathrm{~cm})$, muy superior a las dimensiones aceptadas para los puñales. Podemos admitir como reales estas medidas, pues la misma espada pudo servir de modelo o plantilla en la realización del grabado, cuestión que ya ha sido observada en algunas estelas como la de Meimâo (A. Vasco Rodrígues, 1958, 226). 
Las espadas tipo Rosnoën (figs. 5-6) pueden considerarse como una variante occidental de los tipos Rixheim-Monza, evolución que debió ocurrir en la fase final del Bronce Medio, momento que muestra importantes influencias del Este, las cuales van a modificar profundamente las formas tradicionales en uso en la región atlántica durante esta época (J. Briard, 1965, 101). Estas armas se caracterizan por poseer una empuñadura rectangular o trapezoidal, perforada por cuatro orificios para colocar los remaches en dos pares, aunque también puede tener dos pares de muescas en los bordes para sujetar los remaches de la empuñadura. Los bordes de la lámina corren rectos, en paralelo, acabando suavemente en punta. La longitud de estas espadas puede establecerse alrededor de $50 \mathrm{~cm}$; se trata, por lo tanto, de un arma corta y robusta. En algunos ejemplares existe una nervadura en la empuñadura que se extiende hasta la parte inicial o superior de la lámina. Como puede apreciarse, estas características se adaptan perfectamente al modelo de espada representada en la estela de Fóios.

Según A. Coffyn $(1985,29)$ el llamado grupo Rosnoën comienza a precisarse y extenderse en la transición del Bronce Medio al Bronce Final, aunque parece que esta expansión afecta muy poco a la Península Ibérica. G. Delibes de Castro $(1983-84,112)$ ha señalado que este hecho fue motivado por una lenta penetración en el occidente peninsular de las novedades en los tipos metálicos que se estaban dando en las costas atlánticas de Francia, debido principalmente a su situación marginal respecto a los centros impulsores y a que la asimilación de estas innovaciones se realizó a través de intermediarios bretones y aquitanos. De esta manera se explica el escaso número de armas de influencia Rosnoën o Ballintober en la Península Ibérica, y que continuasen en uso los modelos argáricos más evolucionados. Al final del Bronce Medio, las espadas ibéricas del tipo VII de Almagro Gorbea $(1976,465)$ tenían una longitud mayor $(672$ a $720 \mathrm{~mm})$ que las armas argaricas, las cuales mantienen aún la guarda en forma redondeada, aunque son menos largas ( 440 a $580 \mathrm{~mm}$ ). Su escaso número (El Argar 824, Castelo Bom, Forcas y los imprecisos de Madrid y Lisboa) (fig. 7) se explica al tratarse de un arma de transición, rápidamente desplazada.

Almagro Gorbea señaló la posible existencia de un estadio intermedio entre el grupo de Forcas y el de las espadas pistiliformes, al cual pertenecería la espada de Palencia, más cercana al tipo Rosnoën que la de Forcas. A este mismo grupo podrían pertenecer la espada representada en la estela de Fóios y la espada hallada en Larache, Marruecos, de tipo Rosnoën, más avanzada también que la de Forcas, lo cual demuestra que dicho modelo alcanzó las regiones meridionales del Atlántico. De igual modo, la espada de Herrerías, Almería, de tipo Ballintober, parece confirmar la presencia de espadas atlánticas de la primera fase del Bronce final en la península antes de la llegada de los ejemplares de lengüeta calada y hoja pistiliforme (M. Almagro Gorbea, 1976, 474). En relación con este tipo de hallazgos pueden citarse los ejemplares de puntas de lanza encontrados en Penha (Guimarâes) y Vendas de Culiera (Coimbra, Beira Litoral) que poseen ciertas afinidades con el grupo Rosnoën (A. Coffyn, 1985, 34 y S. O. Jorge, 1988, 95).

En cuanto a su camino para llegar a la Península Ibérica se ha sugerido una vía terrestre que, desde Francia (lugar donde pudo tener lugar la evolución y desarrollo de este tipo de espadas), atravesara los Pirineos, ya sea por los pasos occidentales o por los valles de l'Ariège y del Segre, pudiendo ser este el motivo por el cual los escasos ejemplares peninsulares se han encontrado en el interior y no en zonas costeras. Distinto es el caso inglés, donde se ha propuesto la hipótesis de que los tipos británicos fueron transportados desde Francia, hipótesis confirmada por la presencia de un gran número de espadas Rosnoën gastadas y rotas en el tesoro de Dover, Kent, que parece ser un cargamento francés en ruta hacia Inglaterra (C. B. Burgess, 1988, 15). 

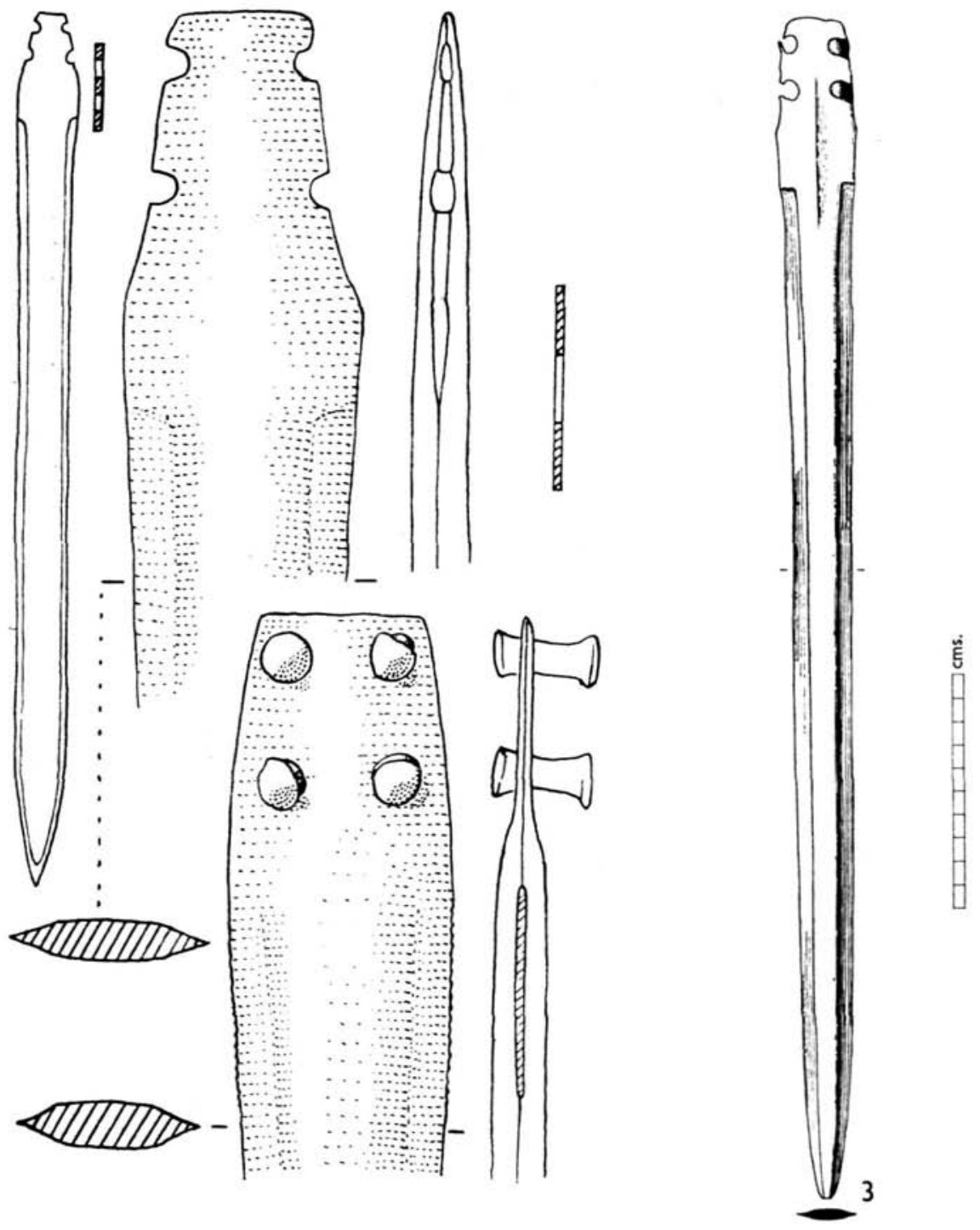

Figura 5: Dos ejemplares de espadas del depósito de Rosnoën (Finistère, Francia). (Según G. Gaucher y J. P. Mohen).

Espada tipo Rosnoën hallada en el río Sena (Rouen, Francia). (Según C. B. Burgess). 


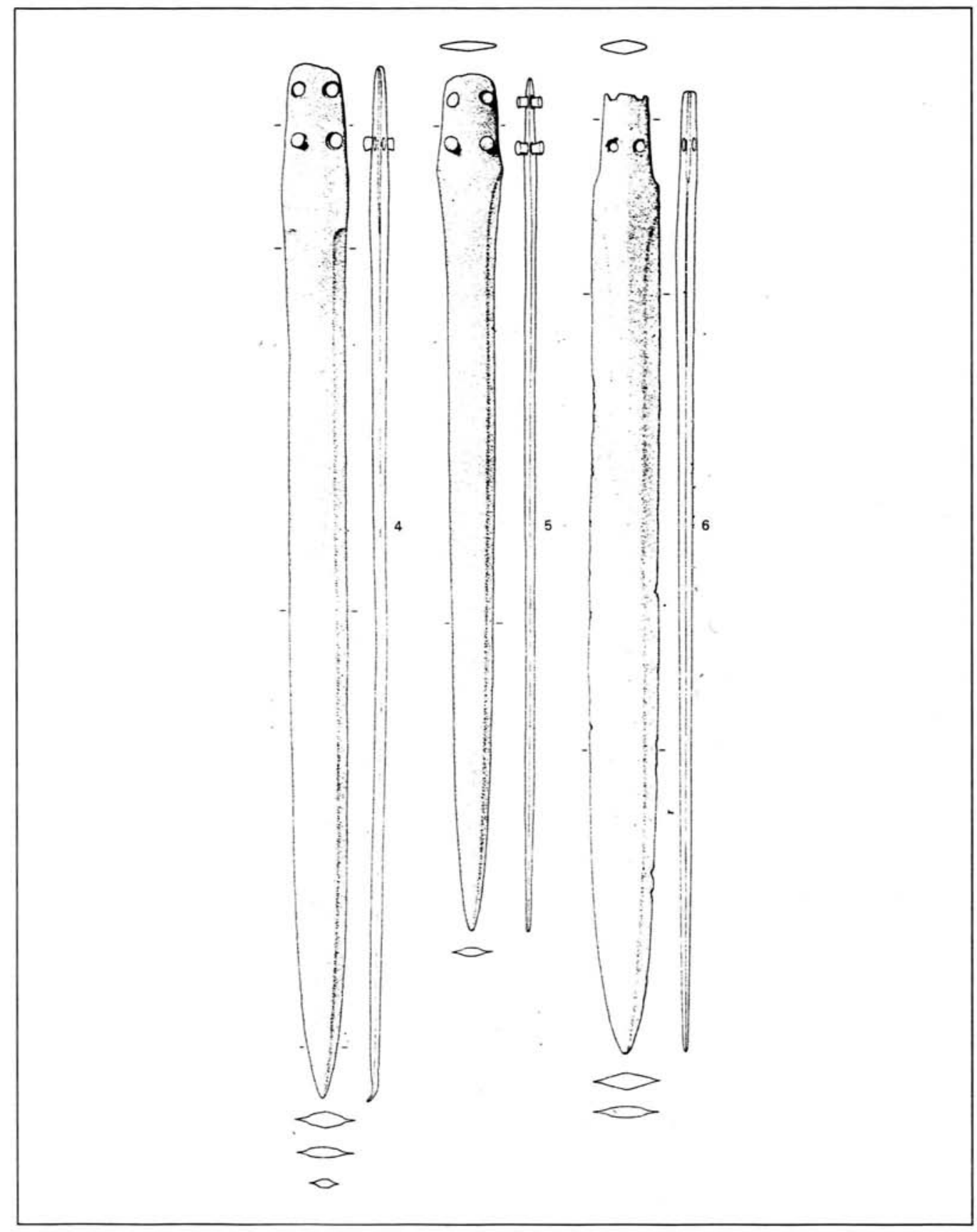

Figura 6: Espadas tipo Rosnoën halladas en Gran Bretaña: ejemplares de Kingston on Thames y Lambeth (río Támesis) y Ambleside. (Según C. B. Burgess). Escala 1/3. 


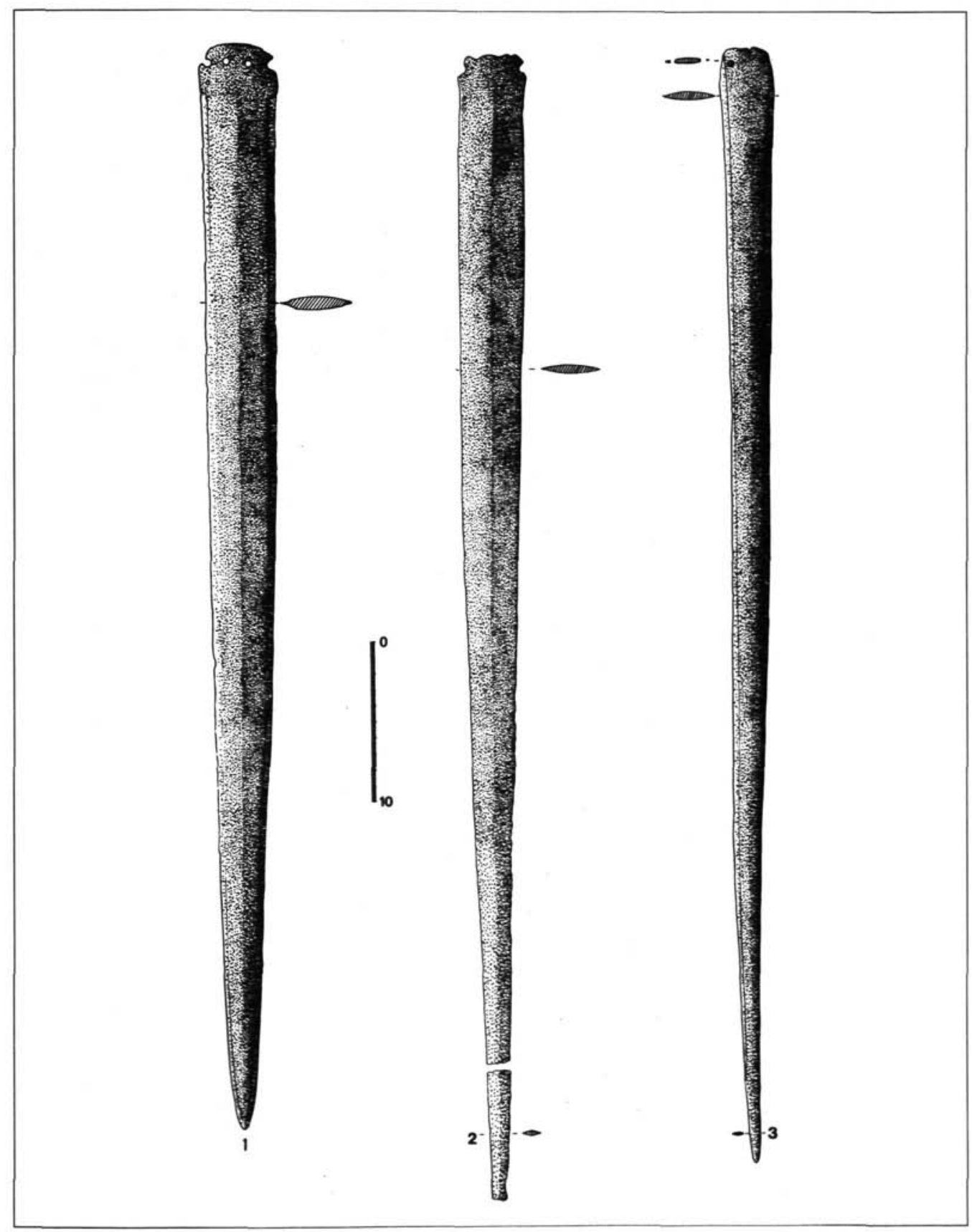

Figura 7: Espadas de Forcas (Orense), Lisboa y Palencia. (Según A. Coffyn).

79 
Hemos considerado este tipo de espada representada en esta estela como un rasgo arcaizante, pero que no resulta demasiado extraño pues la sustitución de armas típicas de los últimos momentos del Bronce Medio por otras más avanzadas de inicios del Bronce Final es lenta y progresiva, pudiendo existir regiones más conservadoras y tradicionales que continúen utilizando estas armas durante bastante tiempo. Por este motivo, la representación de un arma de influencia Rosnoën, con una cronología alta (1200-1050 a. C.), en este tipo de monumentos no es nada extraordinario. En Cognac, Charente (Francia) se ha encontrado recientemente una espada tipo Ballintober de variante continental junto a otra pistiliforme, confirmándose una perduración del primer tipo más larga de lo que se suponía; igualmente, se ha comprobado la pervivencia de tipos industriales de carácter Rosnoën, todavía presentes en depósitos del horizonte de las espadas de "lengua de carpa" (J. Gómez, 1987, 130). Además, este aspecto se repite en otra estela próxima a ésta. Se trata de la estela de Meimâo (fig. 8), en la cual se grabó una espada de características muy particulares, pues, como la espada de la estela de Fóios, responde a un modelo bastante atípico; su forma, su longitud $(60 \mathrm{~cm})$, así como un ligero estrechamiento entre la empuñadura y la lámina, los filos paralelos y la empuñadura con final curvo (y muy posiblemente de remaches), nos remiten a un arma de ascendencia claramente argárica. Ya se ha señalado que en algunas zonas de la península, a comienzos del Bronce Final I, siguieron en uso modelos argáricos, pues apenas llegaron allí aquellos modelos de armas más evolucionados que se estaban produciendo en la zona atlántica. Respecto a la estela de Meimâo, coincidimos con M. Almagro Gorbea $(1977,168)$ en apreciar que, a pesar de su estado fragmentado, la disposición de sus elementos permite establecer su desvinculación con el tipo II A, ya que la situación de la lanza y la espada respecto al escudo no corresponde con el esquema mantenido para este grupo de estelas (este tema será ampliado y comentado en el apartado siguiente). Es muy interesante comprobar como estos rasgos arcaizantes se producen en dos estelas situadas tan próximas una de otra. Además, las espadas de ambas estelas se caracterizan también por la ausencia de empuñadura, pues este elemento de la espada no aparece representado en sus respectivos grabados.

c) Lanza: en cuanto a este elemento, es prácticamente imposible comentar ningún aspecto debido al mal estado en que se encuentra esta parte de la estela, donde posiblemente iría la punta de la lanza. Apuntamos esta última posibilidad pues, en las estelas más sencillas, siempre coincide en paralelo con la posición de la empuñadura de la espada.

\section{La estela de Baraçal:}

a) Escudo: responde al modelo habitual que aparece en las estelas del tipo II A. Es un escudo formado por tres anillos concéntricos, estando los dos exteriores afectados por una clara escotadura en V. Quizá, el único aspecto que sobresale del presente escudo es el tipo de su asidero, con una forma poco común.

b) Espada: se trata de una espada con un aspecto claramente pistiliforme, cuyo paralelo más próximo puede encontrarse en la espada de Vilar Maior, Sabugal (J. de Castro Nunes, 1957, 279) (fig. 9). La bibliografía sobre este tipo de espadas es muy amplia y variada. Su origen es centroeuropeo, de donde pasan rápidamente al mundo atlántico para ser imitadas y exportadas a otras áreas. Tras varios tanteos con láminas híbridas en los cuales se van a elaborar, a partir de estos modelos, otros tipos completamente nuevos, como el denominado Ballintober (donde se mezclan los caracteres Rosnoën y Hemigkofen), los artesanos de esta zona van a crear el modelo atlántico (A. Coffyn, 1985, 34). 


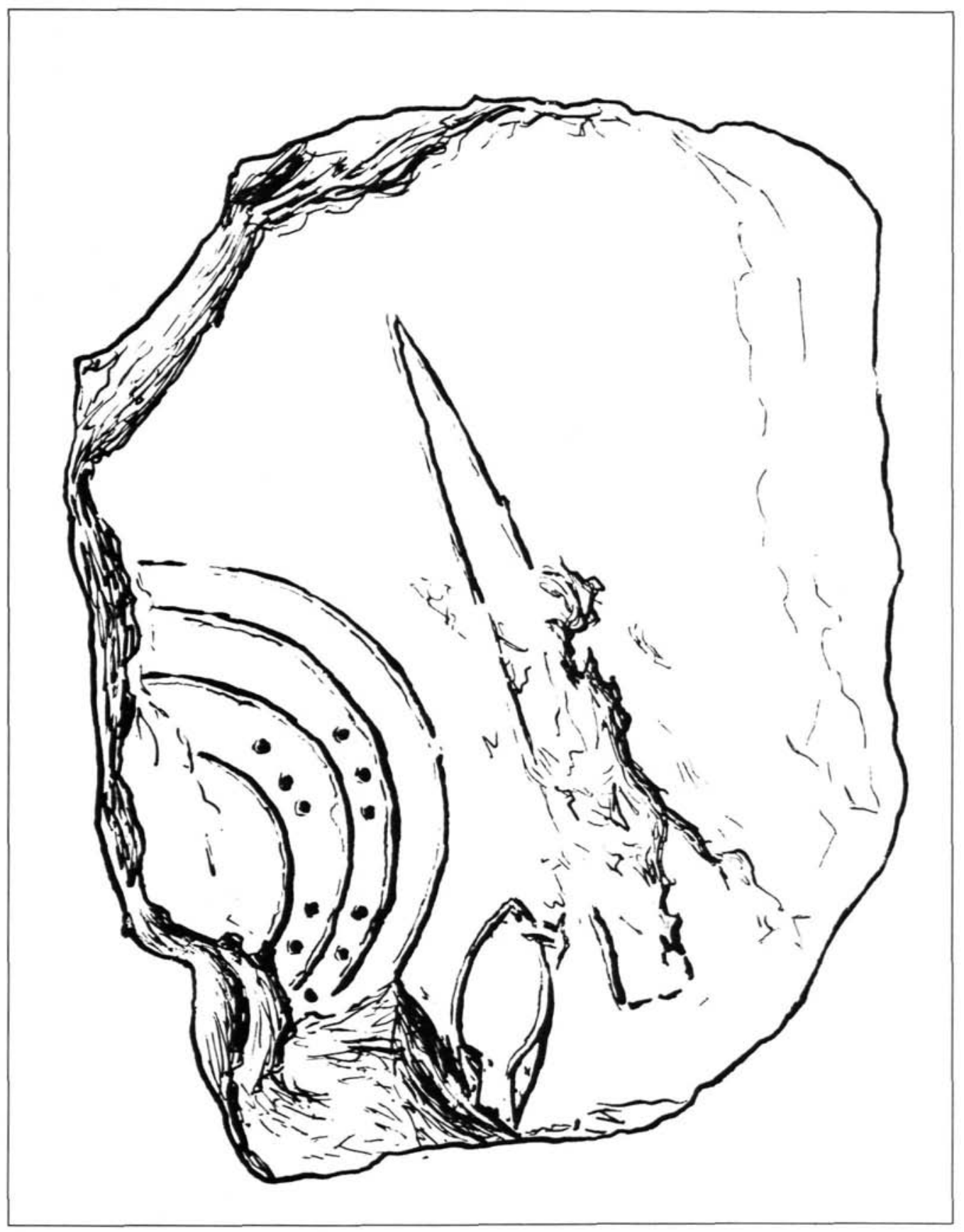

Figura 8: Estela de Meimâo (Castelo Branco, Portugal) 


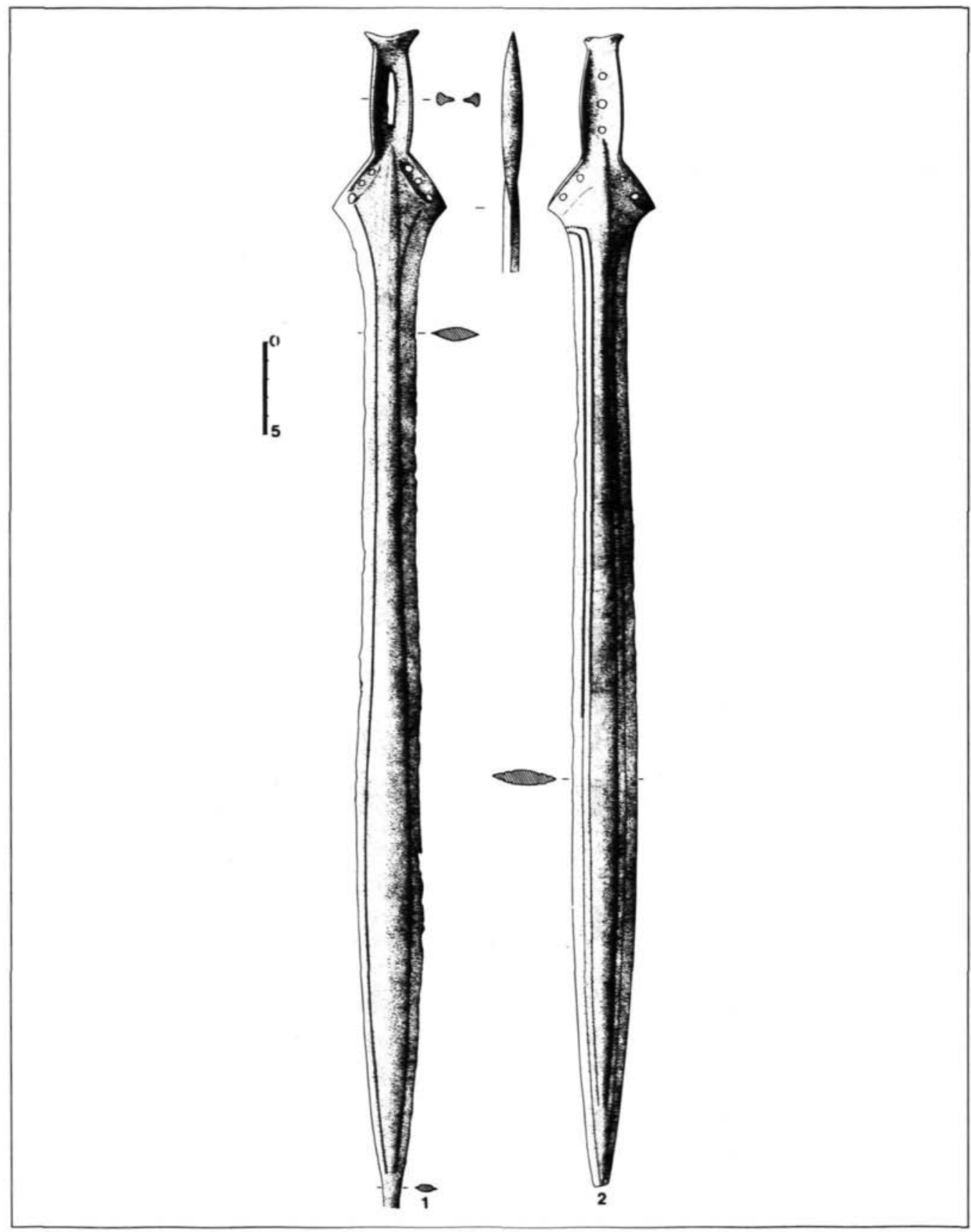

Figura 9: Espadas pistiliformes de Vilar Maior (Guarda, Portugal) y Cognac (Charente, Francia). (Según A. Coffyn) 
En cuanto a la espada de Vilar Maior, J. de Castro Nunes $(1960,95)$ consideró su pureza tipológica como un rasgo de arcaísmo, confirmado por la existencia de tres perforaciones para clavos en la parte inferior de la lengüeta, rasgo que, según M. Almagro Basch $(1940,85)$ era característico de los modelos más antiguos. Es muy posible, por lo tanto, que esta espada sea un ejemplar perteneciente a los inicios de su respectiva serie (posterior desde el punto de vista formal al de San Juan del Río, Orense), presentándose como un modelo bastante antiguo, como así ha apreciado A. Coffyn $(1985,201)$, relacionándola con una espada hallada en Cognac, Charente (Francia) (fig. 9). En un primer momento del Bronce Final II, los talleres peninsulares realizaron copias locales de armas de carácter atlántico importadas a la Península Ibérica, para diversificarse más tarde, gracias a la personalidad de los artesanos hispanos, en las diferentes variantes de las espadas peninsulares. Es la región del Noroeste de la Península Ibérica la que parece ser el foco inicial, pues aquí se han encontrado los ejemplares más antiguos, señalándose su vinculación con el Suroeste francés, bien por vía terrestre (Solucueva, Alava), bien por vía marítima. En cambio, para otros materiales afines a este grupo, como las puntas de lanza de alerones losángicos de origen británico, desconocidas en Francia, sólo puede aceptarse el contacto directo entre las Islas Británicas y el norte de la Península Ibérica (A. Coffyn, 1985, 142), posibilidad también señalada por C. Hawkes $(1969,188)$, basándose en varios hallazgos en el Noroeste y en la región de la Beira portuguesa que confirmaban unas relaciones marítimas directas incluso con Gran Bretaña.

c) Lanza: la punta de la lanza es estrecha y alargada, en forma de hoja de laurel, modelo presente en numerosos depósitos y hallazgos vinculados al Bronce Final atlántico.

d) Técnica utilizada: más que por sus elementos, esta estela destaca singularmente por la técnica elegida en su realización, el relieve, ya que representa el único ejemplar del tipo II conocido hasta ahora en la Península Ibérica con tal característica, pues, como sabemos, uno de los aspectos que distinguen a las estelas "extremeñas" de las losas alemtejanas es la distinta técnica utilizada, el grabado en aquella y el altorrelieve en éstas. Por varias razones que a continuación enumeraremos podemos establecer una relación inmediata entre la estela de Baraçal y otras dos piezas muy diferentes entre sí, las estelas de San Joâo de Negrilhos, Alemtejo (Portugal) (fig. 10) y de Substantion, Montpellier (Francia) (fig. 11).

En cuanto a la primera (M. Almagro Basch, 1966, 116), ambas coinciden en lo que representan y significan cada una respectivamente para el grupo al que pertenecen. La losa de San Joâo de Negrilhos pertenece al tipo I o alemtejano, pero, a diferencia del resto de las otras piezas y frente al uso común del altorrelieve, presenta los elementos (espada y alabarda) grabados. Por lo que respecta a la estela de Baraçal, ya hemos indicado que representa, debido al uso de la técnica del relieve, un caso único entre las estelas del tipo II. De esta manera, ambos ejemplares se presentan como modelos extraños y atípicos en sus correspondientes grupos. La losa de San Joâo de Negrilhos se ha interpretado como una pieza que, posiblemente, representaría los momentos finales de la serie alemtejana, indicando una fase de transición que desembocaría en el grupo de las estelas grabadas. De este modo, se acepta un nexo de unión entre un tipo de monumentos y otro, haciendo derivar a estas últimas de las losas alemtejanas (M. Almagro Basch, 1966, 200). Dicha hipótesis se vería confirmada ahora con el hallazgo de la estela de Baraçal, pues, si la losa de San Joâo de Negrilhos significaba la relación entre las del tipo II y las alemtejanas, esta estela que encaja iconográficamente con las del tipo II, pero que, por su técnica, enlaza de forma directa con las alemtejanas, demostraría la conexión entre las del tipo I y las grabadas.

Es muy posible que los artistas autóctonos de la región centro-occidental de la Península (Extremadura, Beira, Alemtejo) se vieran influidos por las corrientes culturales innovadoras que, 
procedentes del Suroeste, avanzaban y penetraban por aquellas vías naturales que comunicaban ambas zonas (A. Alvarez Rojas y J. Gil Montes, 1988, 313). Este tipo de relaciones se van confirmando con la presencia en regiones del interior tanto de materiales como de aspectos culturales, en cierto modo vinculados al Bronce del Suroeste.

La aceptación de la técnica del grabado en sustitución del altorrelieve podría explicarse por la razón de que ésta última suponía un mayor esfuerzo y coste en la realización del monumento al tener que ser rebajada gran parte de la losa. Creemos que la dureza de algunos materiales utilizados como soporte de la decoración (comprobada en algunas piezas) además de la mayor facilidad, e incluso libertad, que proporciona la técnica del grabado pudieron influir en el progresivo abandono del altorrelieve, hecho que puede confirmarse gracias a la existencia de ejemplares como la losa de San Joâo de Negrilhos y, probablemente, la estela de Longroiva (M. Almagro Basch, 1966, 108) (fig. 12).

Asimismo, esta hipótesis se ve apoyada por otra cuestión formal que se aprecia en aquellas estelas de concepción más sencilla (tipo II A-B), en las cuales, como ya señalamos, las mismas armas reales pudieron haber servido de modelo o plantilla para la ejecución del grabado, sistema que también fue utilizado en las losas alemtejanas. El paulatino abandono de este método puede deberse a una mayor pericia del artista o, muy posiblemente, a las mejores condiciones y posibilidades que ofrecía la técnica del grabado frente al altorrelieve. Este desarrollo y dominio del grabado daría lugar a un proceso evolutivo que culminaría en el acentuado esquematismo que se observa en la representación de los elementos de las estelas más complejas. Es decir, en un primer momento el artista necesitaría la presencia del modelo real para realizar el grabado, sistema que iría siendo abandonado, desembocando en la abstracción de la idea que representa el objeto para después plasmarlo en un diseño esquemático. Además, algunos autores ya han indicado que el hecho de contornear los elementos representados, principalmente las espadas, indicaría una mayor antigüedad frente a las estelas que tienen los elementos rebajados por completo, que serían más modernas (S. Celestino Pérez, 1990, 58). Coinciden en aquellas rasgos arcaizantes como las espadas de filos paralelos, hojas anchas y poco apuntadas.

A pesar de todo lo expuesto hasta este punto acerca de los vínculos que creemos existen entre las estelas extremeñas y las losas alemtejanas, nos parece prematuro, e incluso arriesgado, intentar establecer con absoluta fiabilidad la derivación de un grupo respecto al otro. La estela de Baraçal, no lo olvidemos, representa un caso excepcional en su serie, y aunque aporta nuevos datos, solo permite una mayor aproximación a esta posibilidad.

Más difícil de establecer es el parentesco entre la estela de Baraçal y la de Substantion (A. Soutou, 1962, 521 y M. Almagro Basch, 1966, 125), cuya relación se debe al uso de una misma técnica, el relieve, y a la representación de unos elementos comunes, especialmente el escudo con escotaduras en V. Prácticamente todos los especialistas que se han interesado sobre esta estela la han considerado como un monumento independiente de gran interés en cuanto a su significado cultural y sus posibles vinculaciones con el grupo peninsular. Si bien existe una relación entre ambas estelas, también hay algunos aspectos aún bastante confusos en la interpretación de estas analogías, aumentados por la gran distancia que separa el hallazgo francés de los dos grupos peninsulares. La aparición de una estela de este tipo en Zaragoza (Luna, Valpalmas) (G. Fatás, 1975, 165 y M. Bendala, 1977, 187) indica una interesante dispersión de este tipo de monumentos hacia el ángulo noreste de la península, pero que aporta poco más a la posible interpretación del vínculo existente entre la estela de Substantion y los monumentos hispanos. 


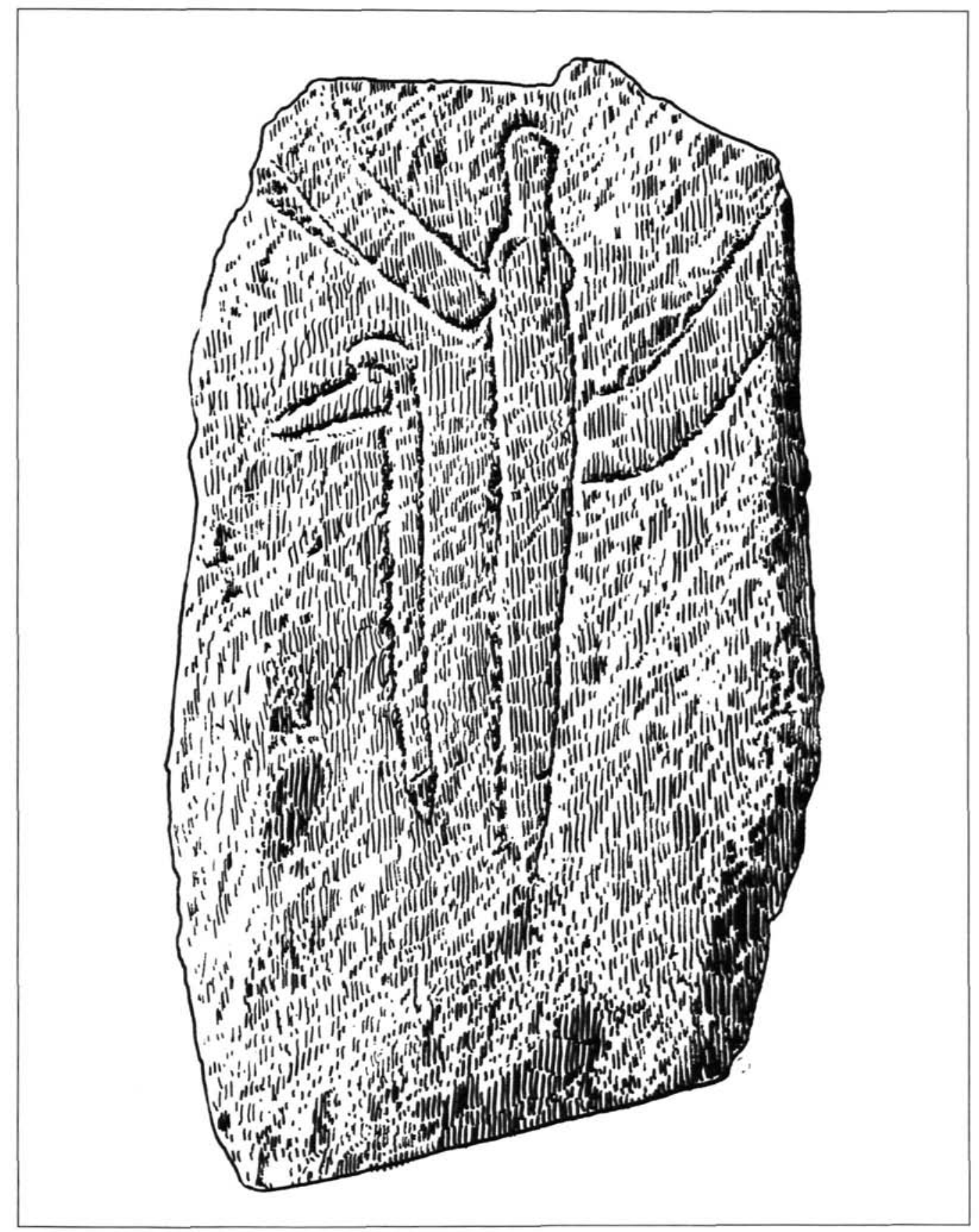

Figura 10: Estela de San Joâo de Negrilhos (Aljustrel, Portugal). (Según M. Almagro Basch) 


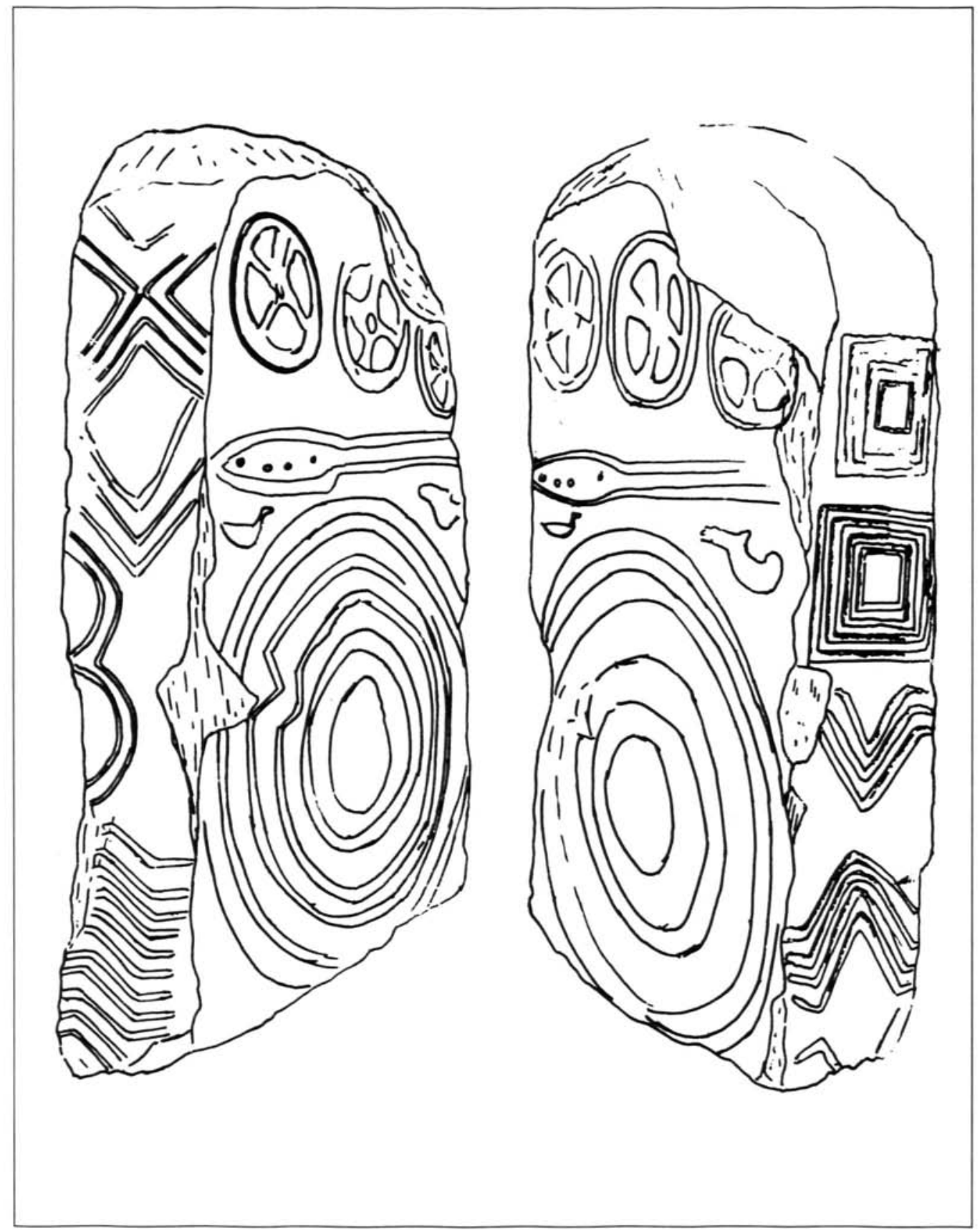

Figura 11: Estela de Substantion (Montpellier, Francia). (Según M. Almagro Basch) 


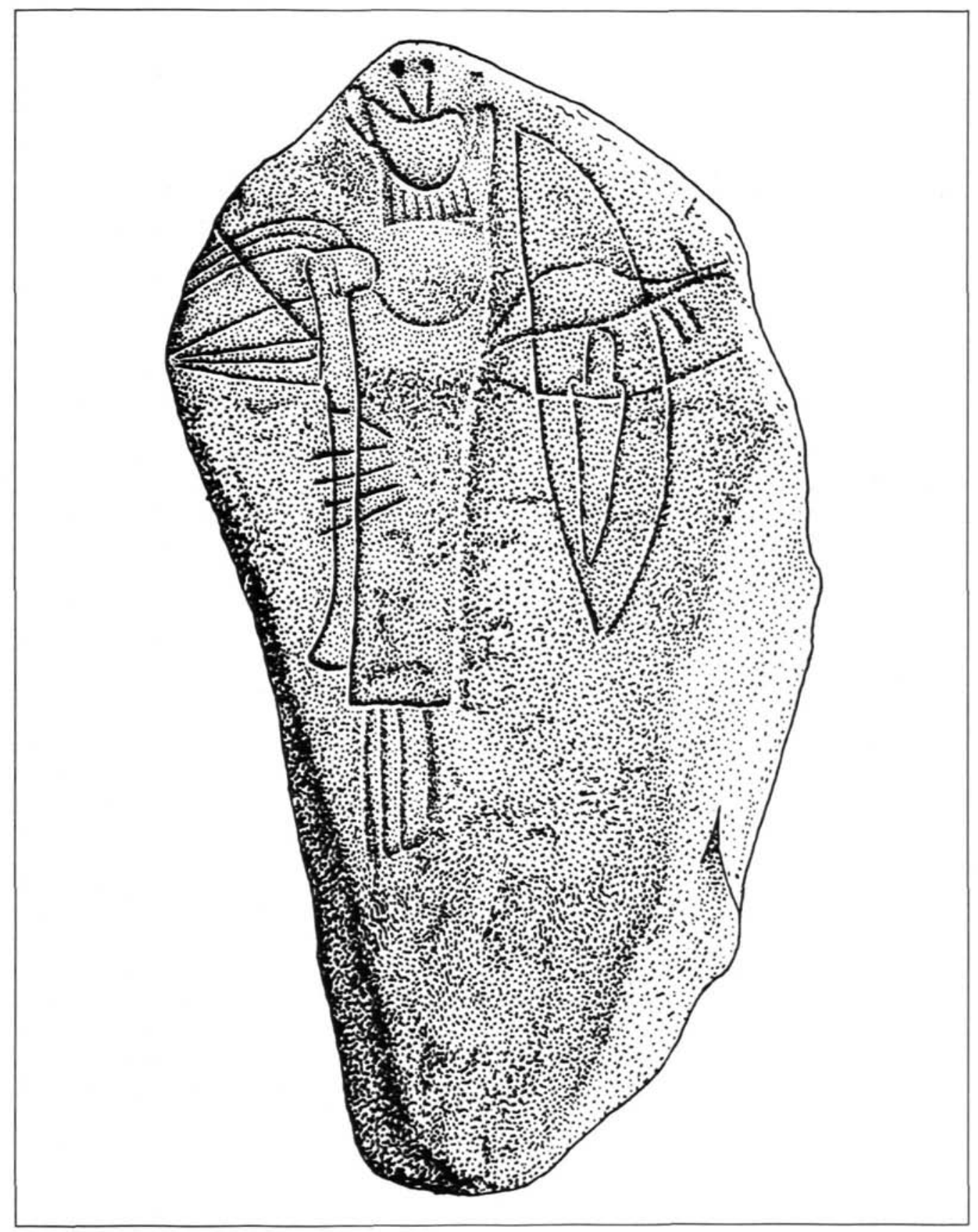

Figura 12: Estela de Longroiva (Guarda, Portugal). (Según M. Almagro Basch). 


\section{CUESTIONES COMPOSITIVAS Y CONCEPTUALES}

Tras estudiar todas las estelas hemos observado la existencia de un esquema iconográficocompositivo que se repite continuamente en las estelas que tienen una concepción más simple (tipo II A y aquellas del tipo II B que recuerdan más a las primeras) y que parece responder a cierta norma aceptada por los artistas que realizaron estos monumentos. La punta de la lanza, la escotadura del escudo y la empuñadura de la espada están siempre representados en este orden y en el mismo lado de la estela, ya sea el izquierdo o el derecho. Este esquema sólo se altera cuando se incorpora un mayor número de elementos, rompiéndose definitivamente en aquellas estelas que incluyen representaciones humanas. Por este motivo, hemos descartado incluir la estela de Meimâo en el tipo II A, ya que, debido a la disposición alterada de sus elementos (espada y lanza), no responde el esquema que hemos determinado, el cual se cumple por completo en el resto de las estelas estudiadas.

Los objetos representados en las composiciones del tipo II A se presentan, por lo tanto, orientados, indicando una dirección, característica que no creemos se deba a la casualidad, sino a una función intrínseca, pero cuyo valor y significado real desconocemos. Es posible que esta norma compositiva tenga un valor simbólico, quizá relacionado con una orientación determinada, pero es muy poco lo que podemos añadir sobre esta característica, limitándonos por ahora a indicar solamente su existencia.

La idea que han mantenido algunos especialistas sobre la posible evolución formal de las estelas, según la cual aquellas del tipo II A serían más antiguas que las restantes, puede ser abordado actualmente con más rigor debido a la mayor información que poseemos. Tras lo argumentado hasta ahora podemos aceptar en primer lugar que en la Alta Extremadura representan un mayor número las estelas más sencillas, cantidad que va disminuyendo según nos alejamos hacia el sur, y, segundo, es precisamente en este tipo de estelas (tipo II A-B) donde encontramos aquellos rasgos más arcaicos. Así pues, y con los datos que disponemos, sería admisible apuntar la posibilidad de que en esta zona, y en un momento determinado del Bronce Final peninsular, quizá más antiguo de lo que se suponía, pudo existir un primer desarrollo de este tipo de monumentos, probablemente vinculados a las losas alemtejanas. De esta forma, las estelas del tipo II A significarían los primeros modelos que inauguran una nueva serie, en las cuales se aprecia la confluencia de algunos rasgos propios tanto de las alemtejanas como de las extremeñas, cuestiones que ya han sido abordadas y desarrolladas en el apartado anterior.

Es significativa también la existencia de numerosas diferencias entre las estelas del tipo II AB y aquellas con esquemas más complejos (II C-D), cuestión ya destacada por M. Varela Gomes y J. Pinho Monteiro $(1977,198)$. Mientras que en las primeras es posible encontrar puntos de conexión entre ellas y las losas alemtejanas (acentuados ahora con el hallazgo de la estela de Baraçal, realizada en relieve), las segundas parecen responder a distintos estímulos o influencias culturales (o una evolución interna), que ya empezaron a significarse en algunas del tipo II B (podemos denominarlas de transición). Incluso estilísticamente, el detallismo que se aprecia en la realización de algunas estelas del tipo II A da paso a un mayor esquematismo que se va acentuando progresivamente.

Un factor que revoluciona el carácter de estos monumentos es la incorporación de la representación humana. Si en las del tipo II A-B lo que parece primar es un modelo vinculado a un posible "culto a las armas", (un ente abstracto), por encima del guerrero que las utiliza, en las últimas se da una mayor importancia a la figura humana, al individuo, que adquiere una nueva dimensión. 
En el primer caso, en el cual ni siquiera aparece representada la figura humana, las armas poseen un carácter especial, diferente al que tendrán en las estelas del tipo II C-D. Están tratadas, no ya como meros objetos de prestigio, que sin ninguna duda son, sino como armas que pueden dar el poder y la victoria a quien las porta, ya que poseen una condición especial, tienen un poder específico que se transmite a aquellos que las portan, situación que no pasa desapercibida entre estas gentes por lo que las asocian inmediatamente a su mundo cultural. Respecto a esta cuestión es muy interesante la valoración de las representaciones de las espadas de las estelas de Fóios y Meimâo. Ambas espadas carecen de empuñadura, solo poseen la zona del enmangue (donde irían los remaches) y la hoja. Aunque el arma ha perdido por completo su funcionalidad, todavía mantiene un carácter especial, con un valor propio, convirtiéndose en un elemento esencial en el lenguaje interno de estos monumentos. A este dato se une, además, el arcaismo de estas espadas, una de tipo Rosnoën y otra de ascendencia argárica, cuya cronología no parece ser contemporánea a la realización de las estelas. El hecho de que la empuñadura ya no se conserve o se haya perdido parece indicar que el resto de la pieza, la hoja, ha perdurado en el tiempo, aunque el arma, como tal, ya no tenga ninguna utilidad. Así pues, estas representaciones nos muestran la importancia que tiene el carácter de estas armas por encima de su funcionalidad, mientras que el conservadurismo de sus formas no hace sino acrecentar su valor interno.

Predomina el arma por encima del individuo, el cual se convierte en sujeto pasivo que únicamente se limita a utilizarlas. El personaje, por lo tanto, no tiene todavía personalidad ni naturaleza de "héroe", sino que por medio de un arma (con un poder propio desarrollado) obtiene, por un lado el símbolo y la fuerza que le distingue de los demás y por otro el posible triunfo, tanto en la vida como tras la muerte. Es este el sentido que puede confirmar la relación existente entre los mundos funerario y religioso y que es inherente a esto monumentos.

Sobre este aspecto, M. Varela Gomes, y J. Pinho Monteiro $(1977,174)$ ya señalaron la posible existencia de una relación conceptual-figurativa entre las representaciones de huellas humanas en algunas losas alemtejanas (Gomes Aires y Ervidel II) y las figuras parecidas que se encontraban en rocas al aire libre en el norte y centro de Portugal, en particular, con los grabados rupestres de la región oriental de la Sierra de Caramulo, en el municipio de Tondela, cuya tradición se puede rastrear desde el Calcolítico. En este lugar, en la gran roca de la estación de Molelinhos, las huellas humanas están asociadas a representaciones de armas. Sobre esta cuestión es interesante la valoración del reciente hallazgo en el valle del Tajo de unas armas grabadas en la roca, en un lugar que ha sido interpretado como un santuario con una tradición bastante antigua (M. Varela Gomes, 1989, 74). El descubrimiento en este sitio de las representaciones grabadas de un escudo con escotaduras en $\mathrm{V}$ en la roca 29 del Cachao do Algarve y de dos espadas, con unas dimensiones parecidas a las reales, en la roca 53 del mismo lugar (fig. 13), plantea nuevas y sugerentes interpretaciones acerca de estas manifestaciones culturales, cuestiones sobre las cuales tenemos pensado volver en futuros trabajos.

En aquellas estelas que poseen una composición más compleja se observa, tras una posible fase de transición, una mayor preeminencia de la figura humana, del individuo, mientras que las armas quedan limitadas a la representación de la panoplia que rodea al guerrero (M. Bendala, $1987,13)$. El motivo que ha provocado este sustancial cambio entre un grupo y otro puede estar relacionado con la transformación que se ha ido gestando en las comunidades que realizaron estos monumentos. La importancia de la figura humana demuestra una mayor jerarquización de la sociedad, en la cual se separa un grupo dominante, de carácter militar, poco numeroso y cerrado, que inmediatamente establece y señala estas diferencias. En este cambio las armas han 


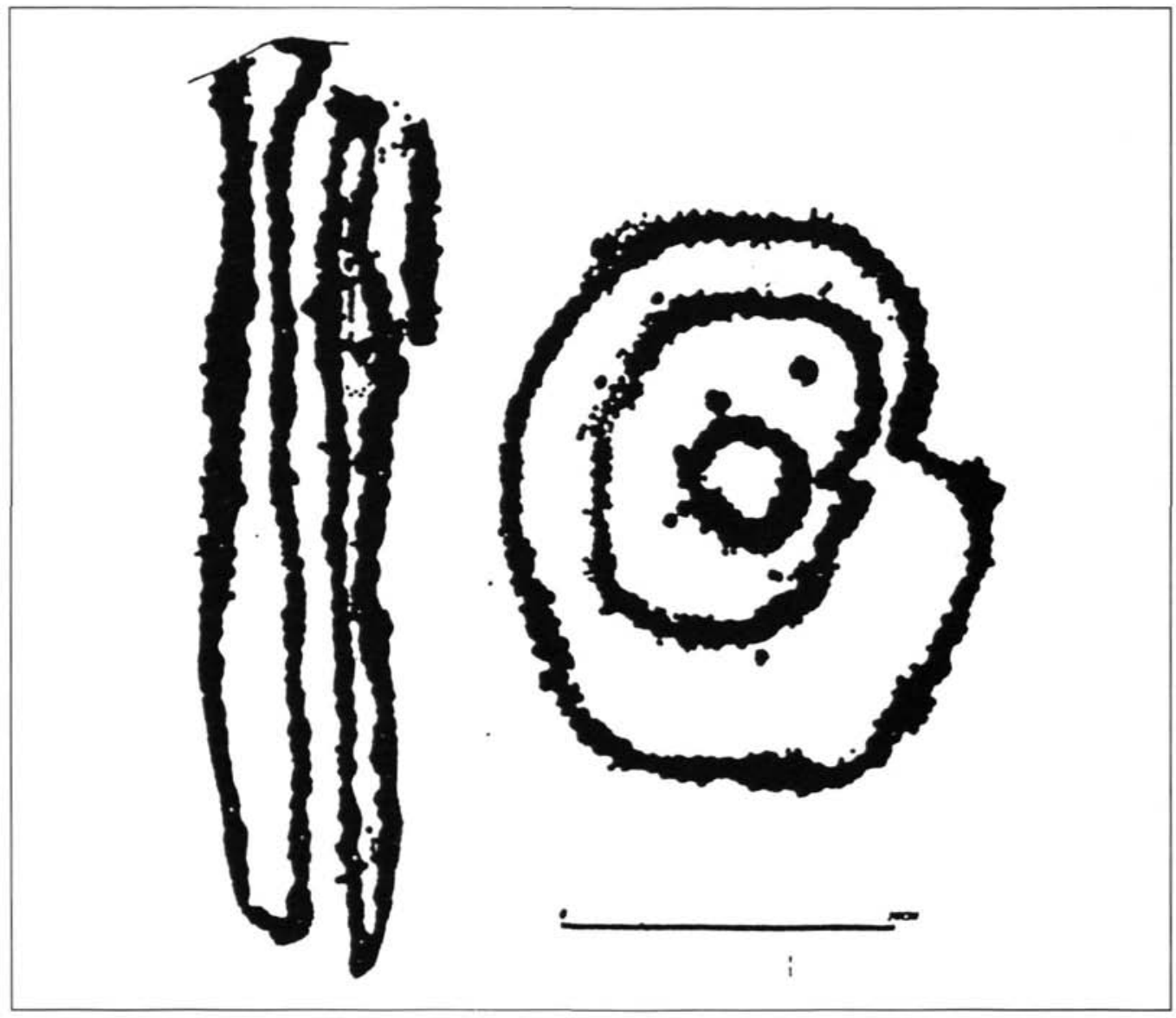

Figura 13: Espadas (Roca 53) y escudo con escotadura en V (Roca 29). (Según M. Varela Gomes)

perdido, casi en su totalidad, el carácter que las definía con anterioridad, siendo ahora el personaje, el "héroe", quien ocupe el papel principal. La figura humana se presenta ya claramente diferenciada del resto de los elementos, como así se comprueba en la composición de este tipo de estelas, de las que el mejor exponente es el ejemplar hallado en Ategua, Córdoba (M. Bendala, 1977, 191). Ya no es el arma "quien" proporciona el poder, sino que es el individuo, ahora plenamente personalizado, incluso heroizado, el que posee los medios y la fuerza necesaria para obtener la victoria, pues tiene el monopolio de un armamento decisivo.

En cuanto a este complejo proceso de heroización, A. Snodgrass $(1990,176)$ ha diferenciado dos significados distintos en la cultura griega. Mientras que en la épica se habla de hombres vivos, principalmente guerreros, que tras su muerte pasan a un oscuro mundo subterráneo, en las obras posteriores se suele aplicar a alguien que ha muerto, quizá recientemente, y que ha sido inmortalizado y honrado mediante algún culto. El primer significado tiene un sentido secular, y el último religioso, casi sagrado, pero no son, según el autor, sucesivos, sino contemporáneos, 
pudiendo tener el segundo una tradición más antigua. Así pues, se suele rendir culto al héroe en un lugar donde se creía que se hallaba su tumba (real o legendaria), en el cual se construía generalmente un templo donde se veneraba a un mortal heroizado. Este mismo carácter se puede apreciar en aquellas estelas más complejas, cuya vinculación con el mundo mediterráneo, a través, posiblemente, de unos contactos ya estables y directos con los colonizadores, parece más evidente que en las del tipo II A-B. Respecto a estas últimas, sus características ya comentadas, parecen indicar una tradición local y una evolución interna, mientras que en aquellas, las del tipo II C, se observan, más que en sus rasgos formales, en su concepto y significado, unos estímulos culturales diferentes. En resumen, en las estelas se recogen y representan elementos que están vinculados a diferentes mundos culturales, pero que por sí solos no confirman otra cosa que la existencia de un momento en el cual es evidente la generalización de contactos entre unas regiones y otras. Estos monumentos nos muestran el reflejo de unas comunidades fuertemente jerarquizadas cuya organización se ha ido complicando debido al desarrollo de una especialización económica regional y de una intensificación en la producción, que ha creado los mecanismos necesarios para una economía autosuficiente. Vemos, pues, que las estelas decoradas se nos presentan como indicadores de una sociedad en plena transformación, cuyos cambios serán en un primer momento de índole económica, relacionados con la especial importancia del comercio y las vías de comunicación, pero que, progresivamente, originarán una profunda renovación socio-política. Creemos que el estudio de este complejo mundo ideológico nos puede proporcionar una excelente información para entender mejor el nacimiento y desarrollo de estos grupos, pues es en estos aspectos donde se refleja con mayor claridad la entidad cultural de un pueblo.

Septiembre 1992 


\section{BIBLIOGRAFIA}

Almagro Basch, M. 1940: "El depósito de la ría de Huelva". Ampurias, II, 85-143.

... 1966: Las estelas decoradas del Suroeste peninsular. B. P. H., VIII, Madrid.

Almagro Gorbea, M. 1976: "La espada de Entrambasaguas. Aportación a la secuencia de las espadas del Bronce en el Norte de la Península Ibérica”. XL Aniversario del Centro de Estudios Montañeses, III, 453-480.

... 1977: El Bronce Final y el Periodo Orientalizante en Extremadura. B.P. H., XIV, Madrid.

Alvarez Rojas, A. y GIL MONTES, J. 1988: “Aproximación al estudio de las vías de comunicación en el primer milenio antes de Cristo en Extremadura”. Trabajos de Prehistoria, 45, 305-316.

AlVAR, J. 1980: "El comercio del estaño atlántico durante el periodo orientalizante". Memorias de Historia Antigua, IV, 43-49.

Aubet Semmeler, M. E. 1975: La necrópoiles de Setefilla, Lora del Río, Sevilla. Barcelona.

... 1989: (coordinadora) Tartessos, arqueología protohistórica del Bajo Guadalquivir. Sabadell.

Barcelo, J. A. 1989: "Las estelas decoradas del Suroeste de la Península Ibérica". Tartessos. Arqueologia Protohistórica del Bajo Guadalquivir (M. E. Aubet), Sabadell, 189-208.

Bendala Galan, M. 1977: "Notas sobre las estelas decoradas del Suroeste y los orígenes de Tatessos". Habis, 8, 177-205.

... 1986: Tatessos. Ha . Gral. de España y América, t. I-1, R. I. A. L. P., Madrid, 593-642.

... 1987: "Reflexiones sobre los escudos de las estelas tartésicas". Boletín de la A. A. A., 23, 12-17.

... 1990: "Tartessos hoy a la luz de los datos arqueológicos y literarios". La Cultura tartésica y Extremadura. Cuadernos Emeritenses, 2, 11-27.

BRIARD, J. 1963: "L’âge du Bronze Final de faciès atlantique". Les civilisations atlantiques du Néolithique a l'âge du Fer. Actes du Prèmier Colloque Atlantique, Rennes, 99-101.

Burgess, C. B. 1968: "The later Bronze Age in the British Isles and Nosth Western France". A. J. A., $125,1-45$.

Burgess, C. B. y Colquhoun, I. 1988: The Swords of Britain. Prähistorische Bronzefunde, Abteilung, IV, 5.

Castro Nunes, J. y Vasco Rodrigues, A. 1957: "Dos nuevas espadas del Bronce Final en Portugal". Zephyrus, VIII, 279-285.

Castro Nunes, J. 1960: “A propósito da estela de Meimâo”. $R$. G. LXX, 86-108.

Celestino Pérez, S. 1990: "Las estelas decoradas del S.W. peninsular”. La Cultura tartésica y Extremadura. Cuadernos Emeritenses, 2, 45-62.

Coffyn, A. 1976: L'Age du Bronze au Mussée de F. Tavares Proença Junior. Castelo Branco.

... 1983: "La fin de l'Age du Bronze dans le centre Portugal". O Arqueólogo Portugués, serie IV, 169-196.

... 1985: Le Bronze Final atlantique dans la Péninsule Ibérique. París.

Coles, J. M. 1962: "European Bronze Age Shields", P. P. S., XXIX, 326-356.

Curado, F. P. 1984: “Uma nova estela do Bronze Final na Beira Alta (Baraçal, Sabugal-Guarda)”. Revista de Arqueologia, 9, Porto, 81-85.

... 1986: "Mais uma estela do Bronze Final na Beira Alta (Fóios, Sabugal-Guarda)". Revista de Arqueologia, 14, Oporto, 103-109.

Delibes De Castro, G. y Fdez. Manzano, J. 1983/84: "Bronce Final atlántico en el Noroeste de la Cuenca del Duero". Portugalia, IV/IV, 111-119.

FATAS, G. 1975: "Una estela de guerrero con escudo de escotadura en "V" aparecida en Cinco Villas (Aragón)”. Pyrenae, 11, pp. 165 y ss. 
Fernandez Castro, M. C. 1988: Arqueologia protohistórica de la Peninsula Ibérica Madrid.

Figuerola, M. G. de 1982: "Nueva estela decorada del tipo II en San Martín de Trevejo (Cáceres)". Zephyrus, 34-35, pp. 173-180.

Gaucher, G. y Mohen, J. P. 1972: Typologie des objects de L'Age du Bronze in France. Tomo I. Societé Préhistorique Française, París.

Gomez, J. 1987: "Les epées du Cognaçais (Charente) el la choronologie des epées du type de ChelseaBallintober en France”. Les relations entre le continent el les Iles Britanniques a l'Age du Bronze. Revue Arq. de Picardie, 125-131.

HAWKES, C. 1969: "Las relaciones atlánticas del mundo tartésico". Tartessos y sus problemas. V Symposium Internacional de Prehistoria Peninsular, 185-197.

HenCKen, H. 1950: "Herzsprung Shields and Greek Trade". A. J. A., 54, pp. 305 y ss.

Jorge, S. Oliveira 1988: "Reflexôes sobre a Pré-história Recente do Norte de Portugal". Coloquio de Arqueología do Noroeste Peninsular, Porto-Baiâo, vol. I. Trabalhos de Antropologia e Etnologia, XXVIII, fasc. 1-2, 85-125.

Oliva Alonso, D. y Chasco Vila, R. 1976: "Una estela funeraria con escudo de escotadura en "U” en la provincia de Sevilla”. Trabajos de Prehistoria, 33, 387-395.

ONGIL, M. I. y SAUCEDA, M. I. 1986: "Vías naturales de comunicación y asentamiento en el Sur de la provincia de Cáceres durante la prehistoria”. Norba-Historia, 7, 155-162.

SNODGrass, A. 1990: Arquelogia de Grecia. Barcelona.

SPROCKHOFF, E. 1954: "Nordische Bronzezeit ud frühes Griechentum". Jahrbuch R. G. Z. M., 1, 28-110.

Soutou, A. 1962: "La stèle au bouclier à échancrures en V de Substantion (Castelnau-le-Leuz, Hérault)". OGAM, Etudes celtiques, XIV, 521-546.

VARELA Gomes, M. 1989: “Arte rupestre do Vale do Tejo. Um santuário pré-histórico”. Encuentros sobre el Tajo: el agua y los asentamientos humanos. Cuadernos de San Benito, 2, 49-75.

VArela Gomes, M. y Pinho Monteiro, J. 1977: "Las estelas decoradas do Pomar (Ervidel, Beja). Estudio comparado". Trabajos de Prehistoria, 34, 165-214.

VASCo Rodrigues, A. 1958: "Novos elementos para o estudo da idade do Bronze. A estela de Meimâo". Zephyrus, IX, 225 y ss. 